\title{
Multilevel Cervicothoracic and Lumbar Pott's Disease: About Three New and Unusual Cases in the Rheumatology Department of the Teaching Hospital of Cocody in Abidjan (Côte d'Ivoire)
}

\author{
Mohamed Diomandé $1^{*}$, Ehaulier Soh Christian Louis Kouakou2, Tamo Estelle Mégné1, \\ Mariam Gbané-Koné1, Abidou Kawele Coulibaly'1, Edmond Eti1 ${ }^{1}$ Marcel N’zué Kouakou' \\ ${ }^{1}$ Department of Rheumatology of University Hospital Center of Cocody, Abidjan, Côte d'Ivoire \\ ${ }^{2}$ Department of Rheumatology of University Hospital Center of Bouaké, Bouaké, Côte d'Ivoire \\ Email: *diomandemohamed48@yahoo.fr, kchristianlouis@yahoo.fr, megnees01@yahoo.fr, \\ mariamgbane05@yahoo.fr, coulibalyabidouk@yahoo.fr, etiedmondoutlook@yahoo.fr, mnkouakou@yahoo.fr
}

Received 5 December 2014; accepted 30 March 2015; published 3 April 2015

Copyright (C) 2015 by authors and Scientific Research Publishing Inc.

This work is licensed under the Creative Commons Attribution International License (CC BY).

http://creativecommons.org/licenses/by/4.0/

(c) (i) Open Access

\section{Abstract}

Pott's disease usually affects two contiguous vertebrae or two spinal levels. The involvement of the three cervicothoracic and lumbar levels is rarely described. Only three cases have been described in the literature to our knowledge. The authors report three new cases of tuberculous spondylodiscitis of cervicothoracic and lumbar site. Our three cases were characterized by symptoms similar to the other topographical forms of Pott's disease. A predisposing factor is often identified like the infection with human immunodeficiency virus. The definitive diagnosis was made in two cases by identifying acid and alcohol-fast bacilli for one case and by histology for the other case. For the third case, there was a diagnostic presumption reinforced by the satisfactory outcome on tuberculosis chemotherapy for a period of 12 months. The multilevel nature of diseases does not influence the effectiveness of treatment of this form of spinal tuberculosis.

\section{Keywords}

Pott's Disease, Spondylodiscitis, Bone and Joint Tuberculosis, Abidjan

\footnotetext{
${ }^{*}$ Corresponding author.

How to cite this paper: Diomandé, M., Kouakou, E.S.C.L., Mégné, T.E., Gbané-Koné, M., Coulibaly, A.K., Eti, E. and Kouakou, M.N. (2015) Multilevel Cervicothoracic and Lumbar Pott's Disease: About Three New and Unusual Cases in the Rheumatology Department of the Teaching Hospital of Cocody in Abidjan (Côte d'lvoire). Open Journal of Rheumatology and Autoimmune Diseases, 5, 23-27. http://dx.doi.org/10.4236/ojra.2015.52005
} 


\section{Introduction}

The spinal tuberculosis represents $50 \%$ of bone and joint tuberculosis (BJT), itself accounting for $2 \%$ to $5 \%$ of all tuberculosis cases [1] [2]. Pott's disease is rife in sub-Saharan Africa contrary to developed country and can affect all ages. It commonly affects the thoracic and/or lumbar spine [3] and usually involves at most two contiguous vertebrae or two spinal levels. Pott's disease involves the cervicolumbar spine or cervicothoracic spine or thoracolumbar spine. Clinical expression can vary from simple pain to severe neurological deficit of limbs and even involve prognosis for life (Pott's disease C1 - C2). The advent of the infection with human immunodeficiency virus (HIV) has contributed to the emergence of unusual forms of BJT with the simultaneous involvement of the three cervicothoracic and lumbar spinal levels. We report three exceptional cases of multifocal and multilevel cervicothoracic and lumbar tuberculous spondylodiscitis observed in the Rheumatology Department of the University Hospital Center of Cocody in Abidjan with emphasis on clinical, diagnosis and therapeutic characteristics.

\section{Cases Presentation}

\subsection{Observation 1}

A 20-year-old man who has been exposed to lung tuberculosis one year before, was hospitalized for chronic inflammatory thoracic pain and lumbar sciatica. The pain has caused a disability in walking, one month before hospitalization. A lingering neck pain and a chronic cough with sputum completed the clinical picture that developed in the context of night fever and poor general condition. Physical examination revealed a cervicothoracic and lumbar spinal syndrome: mild limitation of neck movements, pain on palpation spreading to the thoracic spine, multidirectional lumbar spinal stiffness and positive sign of Lasegue at $30^{\circ}$ on the left. In biology, the erythrocyte sedimentation rate (ESR) was $62 \mathrm{~mm}$ in the first hour, the C Reactive Protein (CRP) at $24 \mathrm{mg} /$, the tuberculin skin test was positive at $15 \mathrm{~mm}$. Direct sputum examination allowed to individualize acid and alcohol-fast bacilli and the HIV serology was negative. The chest radiography showed disseminated reticulonodular opacities. Computed tomography scan (CT scan) of the entire spine revealed a C6 - C7 spondylodiscitis, a T6 - T7 and T7 - T8 spondylodiscitis, with epidural abscess and a spondylodiscitis spreading from L3 to S1 (Figure 1). The diagnosis of bifocal tuberculosis (pulmonary and multilevel Pott's disease) was thus retained. The treatment was based on quadruple tuberculosis therapy combining rifampicin (R), isoniazid (H), ethambutol (E) and pyrazinamide (Z) for 2 months followed by 10 months of RH therapy for a total of 12 months of treatment. The spine was immobilized by brace. The outcome was satisfactory in this treatment and healing was obtained 12 months after.

\subsection{Observation 2}

A 41-year-old patient, HIV positive, on antiretroviral treatment and who presented a tuberculous pleurisy three years before, was hospitalized for diffuse inflammatory back pain. It has gradually provoked a disability in walking and developed over a year period. A month before hospitalization appeared a productive cough. Night fever and progressive weight loss of $15 \mathrm{~kg}$ in a year, were noted. Physical examination revealed a hump in thoracic spine, painful points on palpation of the cervical and lumbar spine with limitation of spinal mobility. There

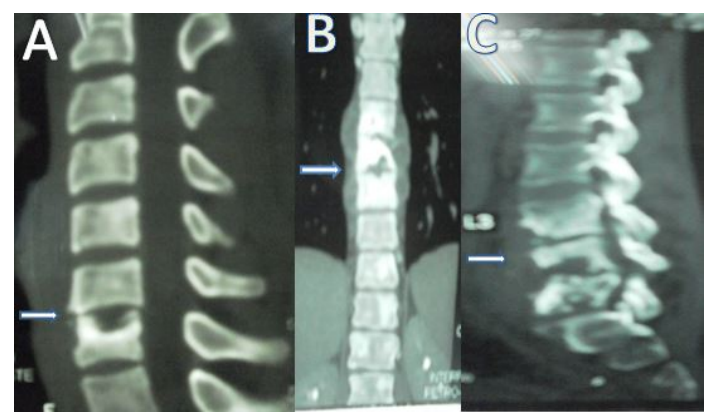

Figure 1. CT scan showing C6 - C7 spondylodiscitis (A), a T6 - T7 and T7 - T8 spondylodiscitis, with epidural abscess (B) and a spondylodiscitis spreading from L3 to S1 (C) (patient 1). 
was no radicular syndrome and no neuro-deficit signs. We have noted three submandibular and jugular adenopathies on palpation, measuring about $2 \mathrm{~cm}$ in diameter. The ESR was $135 \mathrm{~mm}$, the CRP at $117 \mathrm{mg} / \mathrm{l}$ and the tuberculin skin test was not performed. Lymph node biopsy followed by histological examination revealed the presence of a tuberculous follicle. The CT scan of the cervical, thoracic and lumbar spine brought out images of C1 - C2 spondylodiscitis, C4 and T1 spondylitis and a spondylodiscitis at the level of T2 - T3 and L5 - S1 with an epidural abscess (Figure 2). The chest CT showed micronodular interstitial lesions evoking miliary tuberculosis. The retained diagnosis was multifocal tuberculosis: lymph node, lung, multilevel spinal tuberculosis. The outcome was satisfactory on anti-tuberculous treatment (protocol of 2 months of RHZE following by 10 months of RH therapy), corticosteroid and spinal immobilization by brace. The follow-up of the patient was well conducted and he was declared healed 12 months after.

\subsection{Observation 3}

A 21-year-old man, who had a contact with lung tuberculosis one year and 6 months before, was hospitalized for bilateral chronic thoracolumbar radiculalgia of progressive occurrence, badly systematized, of inflammatory character and which became progressively disabling. This symptomatology was associated to a chronic productive cough sometimes hemoptoic in the context of fever, progressive weight loss and night sweats. Physical examination revealed a marked thoracolumbar spinal syndrome: spinalgia on palpation, lumbar hump and multidirectional stiffness with Schöber index at $10+0 \mathrm{~cm}$. A pyramidal irritation syndrome (presence of babinky sign, sharp tendon reflexes in the 4 limbs) was noted without motor deficit. In biology, the ESR was $60 \mathrm{~mm}$ and CRP at $178.24 \mathrm{mg} / \mathrm{l}$. The tuberculin skin test was positive at $18 \mathrm{~cm}$. The search of acid-alcohol fast bacilli in sputum and HIV serology were negative. CT scan of cervicothoracic and lumbar spine respectively brought out spondylodiscitis at the levels C3 - C4, from T5 to T9 and from L3 to S1, with epidural and soft tissues abscesses (Figure 3). A probable multilevel cervicothoracic and lumbar spine tuberculosis was retained as diagnosis. Antituberculous treatment was established for 12 months ( 2 months RHZE following by 10 months RH) and spinal immobilization gave satisfactory results.

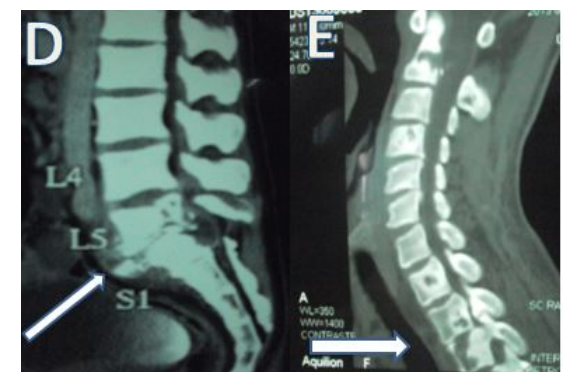

Figure 2. CT scan showing C1 - C2 spondylodiscitis, C4 and T1 spondylitis and a spondylodiscitis at the level of T2 - T3 (E) and L5 - S1 with an epidural abscess (D) (patient 2).

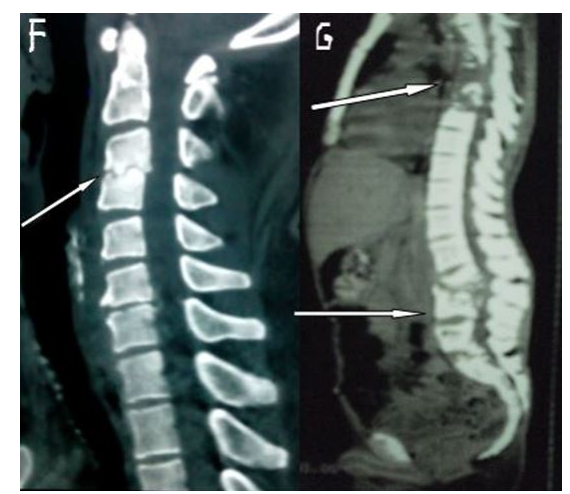

Figure 3. CT scan showing at the levels C3 - C4 (F), from T5 to T9 and from L3 to S1, with epidural and soft tissues abscesses (G) (patient 3). 


\section{Discussion}

Pott's disease usually affects 2 contiguous vertebrae or more whose contamination occurs through blood from a spinal artery which vascularize two adjacent vertebrae [4]. Simultaneous involvement of cervical, thoracic and lumbar spine is very rare, judging by the number of clinical cases reported in the literature. Up to now, to our knowledge only three clinical cases similar to ours have been described [5]-[7]. The first case was reported by Turgut et al. [5] in a quadriplegic patient who was treated surgically. Emel et al. [6] described a cervicothoracic and lumbar spine tuberculosis with many epidural and paraspinal abscesses requiring spinal surgery. In Eljebouri et al. [7], it was about a case with spinal instability eligible for surgery, which was refused by the patient. From the observation of these different reported cases, we notice that there was neurosurgical indication because of neurological deficit and/or spinal instability but it was performed in 2 cases out of 3 . On the contrary, our patients did not really present surgical indication.

BJT is associated in $20 \%$ to $40 \%$ of cases with visceral tuberculosis more of pulmonary origin than of nodal origin [8]. In our cases, patients 1 and 2 had respectively pulmonary and nodal tuberculosis associated. Besides, these sites of visceral tuberculosis allowed to have a bacteriological and histological diagnosis certainty. Let's note that the identification of tuberculosis follicle after analysis of a discovertebral biopsy specimen is even better. We could not perform the trocar needle biopsy because of lack of technical equipment and the high cost of surgical biopsy was a limiting factor. In patient 3 , the epidemiological factors (tuberculosis endemic area, exposition to a contagion of lung tuberculosis), clinical factors (hump, spinal stiffness), biological factors (positive tuberculin skin test), radiological factors (multilevel cervicothoracic and lumbar spondylodiscitis with epiduritis and abscess of soft tissues) and especially the evolution of the disease on treatment (satisfactory progress) prevailed in accordance with the work of Eti et al. [9].

The clinical presentation did not differ from the other cases of Pott's disease. Typically, there is a rather inflammatory spine pain of progressive evolution and chronic in the context of signs of tuberculous impregnation (vesperal fever, poor general condition and night sweats) more or less complete with spinal stiffness as described in our cases. A debilitating condition is most often associated: usually it is HIV infection. In our study, only the patient 2 had a positive HIV serology.

Concerning treatment, the majority of cases described in the literature had a neurosurgical indication contrary to our patients who had a satisfactory evolution with spinal immobilization by brace and anti-tuberculous treatment for a period of 12 months. This RHZE protocol for 2 months followed by 10 months of RH therapy widely practiced in our context was enough to bring healing to the patients.

\section{Conclusion}

Pott's disease at cervicothoracic and lumbar levels is unusual and very rare. Clinical presentation is not very different than the other topographical forms of tuberculous spondylodiscitis. Neither the multilevel nature of the lesions nor the immunodepression HIV has altered the efficacy of treatment.

\section{Conflict of Interest}

None.

\section{References}

[1] Evanchick, C.C., Davis, D.E. and Harrington, T.M. (1986) Tuberculosis of Peripheral Joints: An Often Missed Diagnosis. The Journal of Rheumatology, 13, 187-189.

[2] Monach, P.A., Daily, J.P., Rodriguez-Herrera, G. and Solomon, D.H. (2003) Tuberculous Osteomyelitis Presenting as Shoulder Pain. The Journal of Rheumatology, 30, 851-856.

[3] Kulali, A., Cobanoglu, S. and O’zylmaz, F. (1994) Spinal Tuberculosis with Circumferential Involvement of Two Noncontiguous Isolated Vertebral Levels: Case Report. Neurosurgery, 35, 1154-1158. http://dx.doi.org/10.1227/00006123-199412000-00022

[4] Lee, T.C., Lu, K., Yang, L.C., Huang, H.Y. and Liang, C.L. (1999) Transpedicular Instrumentation as an Adjunct in the Treatment of Thoracolumbar and Lumbar Spine Tuberculosis with Early Stage Bone Destruction. Journal of Neurosurgery, 2, 163-169. http://dx.doi.org/10.3171/spi.1999.91.2.0163

[5] Turgut, M. (2001) Multifocal Extensive Spinal Tuberculosis (Pott’s Disease) Involving Cervical, Thoracic and Lumbar 
Vertebrae. British Journal of Neurosurg, 15, 142-146. http://dx.doi.org/10.1080/02688690120036856

[6] Emel, E., Güzey, F.K., Güzey, D., Bas, N.S., Sel, B. and Alatas, I. (2006) Non Contiguous Multifocal Spinal Tuberculosis Involving Cervical, Thoracic, Lumbar and Sacral Segment: A Case Report. European Spine Journal, 15, 10191024. http://dx.doi.org/10.1007/s00586-005-0989-0

[7] Eljebbouri, B., Baallal, H., Naama ,O., Gazzaz, M. and Boucetta, M. (2012) Spondylodiscite Tuberculeuse Multifocale. Revue Marocaine de Rhumatologie, 20, 42-44.

[8] Pertuiset, E. (2004) Tuberculose osseuse et articulaire des membres. Encyclopedie Medico-Chirurgicale RhumatologieOrthopédie, 1, 463-486. http://dx.doi.org/10.1016/j.emcrho.2004.08.003

[9] Eti, E., Daboiko, J.C., Brou, K.F., Ouali, B., Koffi, K.D. and Kouakou, N.M. (2010) Vertebral Tuberculosis: Our Experience from a Study of 147 Cases in the Rheumatology Department of the University Hospital of Cocody, Abidjan, Côte d'Ivoire. Medecine d'Afrique Noire, 57, 287-292. 